\title{
Opintão
}

\section{A atuação do fisioterapeuta na unidade básica de saúde}

\author{
Andressa Caetano da Veiga*, Carlos Alberto Soares Neves*, Paula Montagna**, Sandra Sayuri Kanda***, \\ Samuel dos Santos Valença, M.Sc**** \\ *Curso de Fisioterapia do UNASP, **Fisioterapeuta, docente do UNASP, ***Fisioterapenta da Unidade Básica de Saúde Capão \\ Redondo, ***Fisioterapeuta, docente do UNASP
}

A necessidade de expansão e melhoramento nos atendimentos oferecidos á população carente fez rever os modelos adotados até a metade do século $\mathrm{XX}$, no qual era priorizado a assistência curativa do atendimento médico individualizado sem qualquer possibilidade de terapias alternativas [1]. Até a década de 70, no Brasil, os recursos à saúde em sua maior parte eram destinados aos hospitais, que ficavam superlotados dificultando os atendimentos. Em 1996, na XII Conferência Nacional de Saúde, foi estendida a toda população brasileira, a assistência à saúde através de um Sistema Único de Saúde (SUS) sendo estabelecido que o atendimento à saúde é um direito do cidadão e um dever do Estado [2].

A Constituição Federal, de 1998, define como princípios do Sistema Único de Saúde: Universalização, Integralidade, Descentralização, Hierarquização e Participação popular [3]. O modelo de assistência do SUS é o de vigilância à saúde denominado de Programa Saúde da Família, que abrange os três níveis de atenção à saúde: primário, secundário e terciário [4]. O Programa Saúde da Família (PSF) existe desde 1994 e sua estratégia é de priorizar as ações de prevenção, promoção e recuperação da saúde das pessoas, de forma integral e contínua. Centralizando os esforços do seu trabalho nas Unidades Básicas de Saúde, que são capazes de resolver, com qualidade, cerca de $85 \%$ dos problemas de saúde da população, diminuindo o fluxo dos usuários para os níveis mais especializados "desafogando" assim os hospitais. O atendimento prestado pode ser na Unidade Básica de Saúde ou no domićlio, quando considerado necessário. Os Agentes Comunitários de Saúde (ACS) são os elos fundamentais entre a comunidade e os serviços de saúde. Os agentes compõem as Equipes de Saúde da Família - ESF [3].

O Ministério da Saúde [3,4] lançou, em 1999, o Manual para a Organização da Atenção Básica e define que "Atenção Básica é um conjunto de ações, de caráter individual ou coletivo, situadas no primeiro nível de atenção dos sistemas de saúde, 
voltados para a promoção da saúde, a prevenção de agravos, o tratamento e a reabilitação". As ações preventivas vêm sendo cada dia mais utilizadas na área da saúde. A prevenção ou promoção da saúde é uma maneira de estar diminuindo gastos futuros para os cofres públicos e evitar grandes epidemias que causam problemas à comunidade. Para Ribeiro [1], prevenção é a intervenção mais precoce no processo saúde-doença, enquanto para Candeias [5] e Czeresnia [6] promoção da saúde são ações que visam a modificações no estilo de vida, ou seja, adoção de hábitos de vida saudáveis, na tentativa de diminuir o risco de adoecer e morrer. Para que estes programas de promoção da saúde tenham bom andamento são necessários profissionais devidamente capacitados e desempenhando plenamente suas atividades. Ribeiro [1] refere que os profissionais da área de saúde precisam ter competência técnica e compreensão dos problemas de saúde da comunidade onde atuam e tenham noção de que assistência á saúde é muito mais que tratar a doença.

\section{Atuação da fisioterapia na promoção da saúde}

Por muito tempo a fisioterapia ficou excluída dos serviços básicos de saúde pela sua atuação, na maioria das vezes na reabilitação, esquecendo-se da prevenção e promoção da saúde. Para Sampaio [7] o profissional fisioterapeuta vem desenvolvendo suas ações voltadas para a atenção secundária e terciária, atuando em clínicas, consultórios privados ou hospitais, com um papel de pouco destaque na atenção primária.

Antigamente a fisioterapia era definida "como tratamento de pacientes incapacitados por doenças, traumatismo ou perda de parte do corpo, através de exercícios terapêuticos, calor, frio, água, luz, eletricidade, ultra-som ou massagem" [8]. A fisioterapia atual vem sendo definida "como ciência da saúde voltada ao estudo, prevenção e terapêutica dos distúrbios cinéticos funcionais dos órgãos e sistemas do corpo humano" [9]. Para Rebelatto et al. [10] "o fisioterapeuta tem como dever a promoção da saúde da população. Para isso, deve haver uma atenção direcionada para assistência ao indivíduo não somente após estar acometido por alguma patologia, mas uma preocupação com a promoção e a manutenção da saúde e a prevenção de doenças". Fazer prevenção é uma maneira de agir antes que o problema ocorra. A resolução n. ${ }^{\circ} 10$, artigo $1^{\circ}$ do Código de Ética do profissional de Fisioterapia e Terapia Ocupacional, mostra que a prevenção deve fazer parte da atuação destes profissionais. "Artigo $1^{\circ}$ - O fisioterapeuta e o terapeuta ocupacional prestam assistência ao homem, participando da promoção, tratamento e recuperação de sua saúde".

O fisioterapeuta e demais profissionais da saúde devem atuar na prevenção de doenças e maus hábitos que possam prejudicar a saúde dos indivíduos. Existe, portanto, um vasto campo de atuação para o fisioterapeuta em saúde pública podendo promover uma melhor qualidade de vida à comunidade.

\section{Limitações enfrentadas pela fisioterapia na promoção da saúde}

O trabalho da fisioterapia na promoção da saúde nos serviços públicos é uma nova forma de atuação e, por isso, ainda passa por dificuldades técnicas, necessitando de adaptações e esforços. Um dos problemas enfrentados diz respeito à formação acadêmica dos fisioterapeutas, que são despreparados para este tipo de trabalho. Para Afonso [11] "a formação discente parece não estar voltada para a questão da prevenção, mas sim, prioritariamente, para as técnicas de tratamento reabilitadoras". Segundo Rebelatto [10] 
para que os fisioterapeutas tenham uma melhor qualidade de atuação depende, em grande parte, do que é ensinado na formação destes profissionais, mas por outro lado depende também de quanto os docentes e responsáveis por esses cursos são capazes de transformar o conhecimento disponível em comportamentos profissionais e das próprias características de qualidade e quantidade do conhecimento disponível. Outro problema enfrentado é a falta dos serviços de fisioterapia e a escassez de profissionais fisioterapeutas. A falta de recursos terapêuticos nas UBS dificulta o trabalho do fisioterapeuta que se sente limitado na atuação, seja devido à grande demanda da população ou quanto à falta de equipamentos e até espaço físico. Soma-se a esse fator a pouca ou nenhuma experiência em atuação na rede básica, porque o fisioterapeuta na sua maioria está capacitado para atuar em serviços com melhores recursos técnicos.

$\mathrm{O}$ atendimento domiciliar numa comunidade de baixa renda é outra nova realidade que precisa ser encarada pelo profissional fisioterapeuta. Ao atender em domicílio ele se vê forçado a conviver, formar vínculos com os familiares e a própria comunidade adjacente, causando muitas vezes angústia no profissional e possível distanciamento dos usuários. A atuação do fisioterapeuta nas UBS fica limitada por vários fatores como o número insuficiente de profissionais disponíveis na rede básica, a urgência no tratamento das seqüelas, sendo necessário priorizar o tratamento curativo em detrimento à prevenção.

Os pacientes também enfrentam dificuldades no acesso ao serviço de fisioterapia da rede pública. Exemplo disso são as enormes listas de espera para receber o primeiro atendimento e quando o recebe, às vezes, enfrentam barreiras como: dificuldade para deslocamento (Residência - UBS) e dificuldades financeiras para o transporte até a UBS, perdendo em alguns casos a oportunidade de recuperação e agravamento do problema.

\section{Alternativas de terapias}

Existem vários trabalhos que propõem medidas para prevenção e alternativas de tratamentos para pacientes com poucas complicações e até mesmo para pacientes crônicos e/ou complexos. Cabe ao profissional de fisioterapia adequar-se e até mesmo criar suas próprias alternativas para suprir a demanda dos atendimentos nas UBS. Além do atendimento individualizado, as atividades em grupo têm-se mostrado uma das possibilidades de conduta fisioterapêutica. Atividades em grupo podem contribuir para a diminuição da demanda por atendimentos individuais e têm sido fator importante na adesão ao tratamento. Nas referências citadas neste trabalho foram encontrados vários métodos diferentes de se realizar atividades em grupos. Por exemplo: em um trabalho realizado na comunidade do Gratão e Maria de Nazaré em Pernambuco no período de março de 1998 a julho de 2000, os fisioterapeutas de uma maneira geral realizavam atendimentos para reabilitação, atividades em grupo de: postura, hipertensos, diabéticos, gestantes e prevenção de incapacidades em hanseníase [1]. Um outro exemplo está sendo realizado desde 1990 no Centro de Saúde São Gabriel na cidade de Belo Horizonte onde os fisioterapeutas atuam em programas de orientações e atividades físicas para hipertensos, diabéticos e crianças com asma [7]. A Universidade Federal de Santa Maria tem desenvolvido atividades do Programa Nacional de Combate ao Fumo, em conjunto com a secretaria Municipal de Santa Maria e a Igreja Adventista, por meio de "Cursos para deixar de fumar" desde 1993. Realizam também palestras educativas em escolas e bairros da cidade sobre tabagismo, em feiras e exposições por meios de painéis e esclarecimento aos visitantes [12].

Ao fisioterapeuta, a realidade é dura, às necessidades da população que o cerca são reais, mas existe possibilidade quanto à construção de novos caminhos em sua profissão. 


\section{Referências}

1. Ribeiro KSQ. Atuação da fisioterapia na atenção primária à saúde - Reflexões a partir de uma experiência universitária. Fisioter Bras 2002;3:311-318.

2. Almeida C. Saúde e equidade nas reformas contemporâneas. Saúde em debate 2000;24:6-21.

3. Brasil. Ministério da saúde. Manual para organização da atenção básica. Brasília, 1999.

4. Souza MH. A estratégia de saúde da família no Brasil. Jovem Médico 1999;1:1-11.

5. Candeias NMF. Conceitos de educação e de promoção em saúde: mudanças individuais e mudanças organizacionais. Rev Saúde Pública 1997;31:1-8.

6. Czeresnia D. The concept of health and the difference between prevention and promotion. Rev Saúde Pública 1999;15:1-14.

7. Sampaio RF. Promoção de saúde, prevenção de doenças e incapacidade: a experiência da fisioterapia/UFMG em uma unidade básica de saúde. Fisioter Mov 2002;15:19-23.

8. Shestak R. Fisioterapia prática. São Paulo: Manole; 1980.

9. Menezes RG. Entrevista. Fisio\&terapia 1998;2:12-14.

10. Rebelatto JR. Fisioterapia cotidiana: ações profissionais e decorrências para a população. Rev Fisioter Univ São Paulo 1998;5:36-48.

11. Afonso JL. Fisioterapia na atenção primária em saúde. Ícone 1994;2:45-75.

12. Martins JS, Fröemming MB, Ribeiro EC. Fisioterapia na promoção da saúde respiratória e no combate ao tabagismo. Fisioter Mov 1999;12:53-60. 